\title{
HOW DO YOU “DO” EVENT MANAGEMENT EDUCATION (EME)? A CASE STUDY OF EVENT MANAGEMENT HIGHER EDUCATION AWARDS
}

\author{
W. GERARD RYAN \\ University of Salford, Salford, Greater Manchester, UK
}

\begin{abstract}
This case study of Event Management Education (EME) was conducted at the beginning of 2014. It presents the preliminary findings obtained from a questionnaire completed by EME lecturers and will contribute to the progress and direction of future EME awards. There is an indication from these preliminary findings that while lecturers are confident of the quality of student they produce, they are aware difficulties exist in the teaching of EME. Also, while there is a desire from award leaders to modify EME awards, other influences from within the school may restrict these objectives. Alongside these findings, there is good evidence of subject knowledge and industry experience from those who teach these awards.
\end{abstract}

Key words: Event management; Education; Curriculum design; Professionalization; Pedagogy; Higher education

Introduction

Anyone can manage an event. However, to be an event manager requires a complex and diverse set of skills, many of which will be specific to the type of business the company or individual will be trading in. The event industry itself is hugely diverse and its requirement for suppliers covers an enormous breadth of professions, from staging and structures to water management and waste recycling (Business Visits and Events Partnership [BVEP], 2014) with an abundance of other trades in between. Significant capital investment from governments and operators continue in developing the necessary facilities and infrastructure to accommodate the events industry (Presbury \& Edwards, 2005) and considering the importance of events on so many levels, appropriate education in the management of events is paramount to the industry as mistakes caused by the lack of appropriate management competencies can be costly, if not disastrous (Perry, Foley, \& Rumpf, 1996). According to Universities and Colleges Admissions Service (UCAS), Event Management Education (EME) is currently delivered at 88 institutions across the UK, with 231 higher-education courses currently available (UCAS, 2014). The majority of these courses (awards) are classed by way of the Joint Academic Coding System (JACS) N820 code "Event Management.” 
Considering this multifaceted area of education and the fact that the number of higher education institutions (HEIs) offering an EME award in March 2006 was 44 (Bowdin, McPherson, \& Flinn, 2006), a review of EME practices and methods has been undertaken. This case study of EME brings together the broad make up and delivery practices of EME with observations from those who deliver the awards. This is then triangulated with desk research in order to present a better understanding of the current delivery methods compared to the demands of the main stakeholders.

In conducting this research it is recognized that the EME curriculum develops on an annual basis and this research is not intended to provide superficial conclusions. Instead, data from the study have unearthed some less apparent realities and therefore should go on to provide a medium to inform how and/or if a need to develop the curriculum in the future, beyond its current natural path is necessary. The events industry, it's supporting and closely related organizations should also benefit from the data as a clearer understanding of current practices and content of EME awards is presented. Therefore, this article aims to contribute to knowledge of EME and presents the preliminary findings of a survey into EME that considers the background of those who deliver EME, what subjects are taught, the specialist knowledge areas of those who teach, and if an award has a particular focus. It also considers the design of EME awards with consideration for the event management National Occupational Standards (NOS) and whether lecturers would reexamine their current means of delivery.

\section{Rationale and Context}

A great deal more interest in EME is evident through the dedicated event management journals with significant research being geared towards professionalization, with education a fundamental aspect. Furthermore, a number of factors have contributed to open debates on the quality of education being provided. Unusually, the unique challenge EME appears to have to address is an obligation to prove the necessary skills event managers require can be taught through an EME award.

This challenge is kindled by suggestions that EME is providing event management graduates entering the industry only to fill nongraduate positions (Eade, 2010; Pool \& Sewell, 2007). Alongside this, People1st (2010) established that some employers bring into question the ability of certain lecturers teaching event management awards, suggesting it is detrimental (to either the industry or the award) if lecturers have no first-hand experience of running events and instead depend on an academic understanding. Raising the same concern during the International Conference on Events (ICE), one panel member flippantly questioned how many lecturers had actually set up a music stand (ICE, 2013). This may not be an appropriate identification or analysis of industry need but it does expose a debate that perhaps exists in industry about the suitability of EME lecturers. These observations highlight some of the challenges being faced by EME HEIs and the complexity of the problems that exist for those who design EME awards.

What is perhaps most difficult to comprehend for those involved in EME is when event management graduates are excluded from the recruitment process because of a prejudice towards EME awards (Benjamin, 2014). This matter is intensified because there are no standards of entry (degree, certification, licensing, or other form of credentialing) for the event management industry (Nelson \& Silvers, 2009). The explanation for disregarding EME graduates is that EME institutions do not appear in the top 20 Complete University Guide in the UK (CUG, 2014) where, it is suggested, graduates should first be sourced. In support of such methods, Giles (2013) advises that outside of a Russell Group institution, what students are paying for is a tumbleweed degree that is going to float straight past employers. The significance of these comments to EME is thought provoking as the highest placed university that provides an event-related award in the UK is ranked 28th in the Complete University Guide and does not actually deliver the N820 event management award.

In response to these disparaging accounts of EME, more favorable assertions on the strength of EME and its graduates have also been reported (Edwards, 2014) with backing from a wide range of event management stakeholders. Also, Junek, Lockstone, and Osti (2007) suggest that students believe an event management degree will provide them with the necessary skills and knowledge to 
pursue jobs in their chosen field. But, while the multidisciplinary aspect of the industry offers a wide range of employment positions, problems exist in the lack of consistency in terminology throughout the industry (Nelson \& Silvers, 2009), contributing to challenges in career entry and progression by job designation.

\section{Method}

This research has adopted a largely interpretivist rather than positivist epistemological approach and is largely a qualitative study that forms part of a much broader case study into EME. In order to generate the data required for the survey, it was necessary to produce a questionnaire for academics who deliver EME awards to gather qualitative and quantitative data. By adopting a mixed-methods approach and by presenting certain themes, data could be gathered by allowing respondents the opportunity to make choices from set lists to provide figures on the more widespread understandings of EME content. At the same time, by providing respondents a number of opportunities to put forward personal suggestions, if in their view certain areas of EME had been overlooked in the original question, a more complete understanding of EME has been created. Therefore, a phenomenological understanding of current EME practices is achieved. A positivist understanding of EME may be considered by some to be essential, but in reality, such an understanding is impossible to achieve given the many complications that exist in obtaining the necessary data to be so precise.

When collecting data, it is generally the case that the larger the sample size, the more reliable and precise the survey findings are (Veal, 2011). However, Travers (2001) suggests that once a qualitative approach towards the research has been decided, there are no benefits in working with large data sets, because these encourage a positivist mentality towards analysis. What is important to this research is ensuring a sufficient sample of the population has been reached while ensuring involvement with EME is central to the sample's core activity.

In order to test some of the ideas for this study, a questionnaire was piloted in one HEI. Based on the initial responses and comments, a revised version of the survey was then constructed. The revised version was posted on a national academic mailing list forum designed specifically for higher education and research communities. The forum in question is subscribed to by a mix of 187 event management professionals and academics with a direct interest in EME. There are several limitations to using this research approach as the sample size is limited to the membership of the forum, the ability to participate either because of availability or the limited time span in which the questionnaire was available, and the occupation of the forum members who would have chosen not to complete it based on the belief that it was specifically for those who teach EME. The questionnaire was closed at the beginning of March 2014 and was completed by 39 members of the forum, with a response rate of $21.91 \%$ being achieved. Ninety-one percent (29) of the respondents declared they came from the UK, 3\% (1) from mainland Europe, and 6\% (2) from elsewhere.

\section{Results}

As shown in Figure 1, respondents were asked what, if any, experience EME staff has of event management. The data gathered suggests that knowledge and industry experience is widespread with only one respondent (3\%) selecting the option "no previous hands-on industry experience" of event management. Of those members who provided data shown in Figure 1 option 4, "I came from another area of work into events management education," the answers provided all have some bearing on events. These included Sport Business, Leisure \& Events, Sport \& Recreation, Tourism \& Hotel Management, and Engineering. Similarly, those who selected option 5 "other, please state," still have strong connections with event management. Two responses were provided as follows: (a) I worked in hospitality with events as part of my remit and I continue to organize events, and (b) I came from hotel management.

Earlier discussions and research that discusses the background of EME staff (Benjamin, 2014; ICE, 2013; People1st, 2010) brought into question the absence of practical knowledge and experience in EME. Some stakeholders in the sector consider this to be detrimental to the award and graduate. This is an extremely complicated debate and with 231 awards available in the UK, a considerably greater number of lecturers are involved 


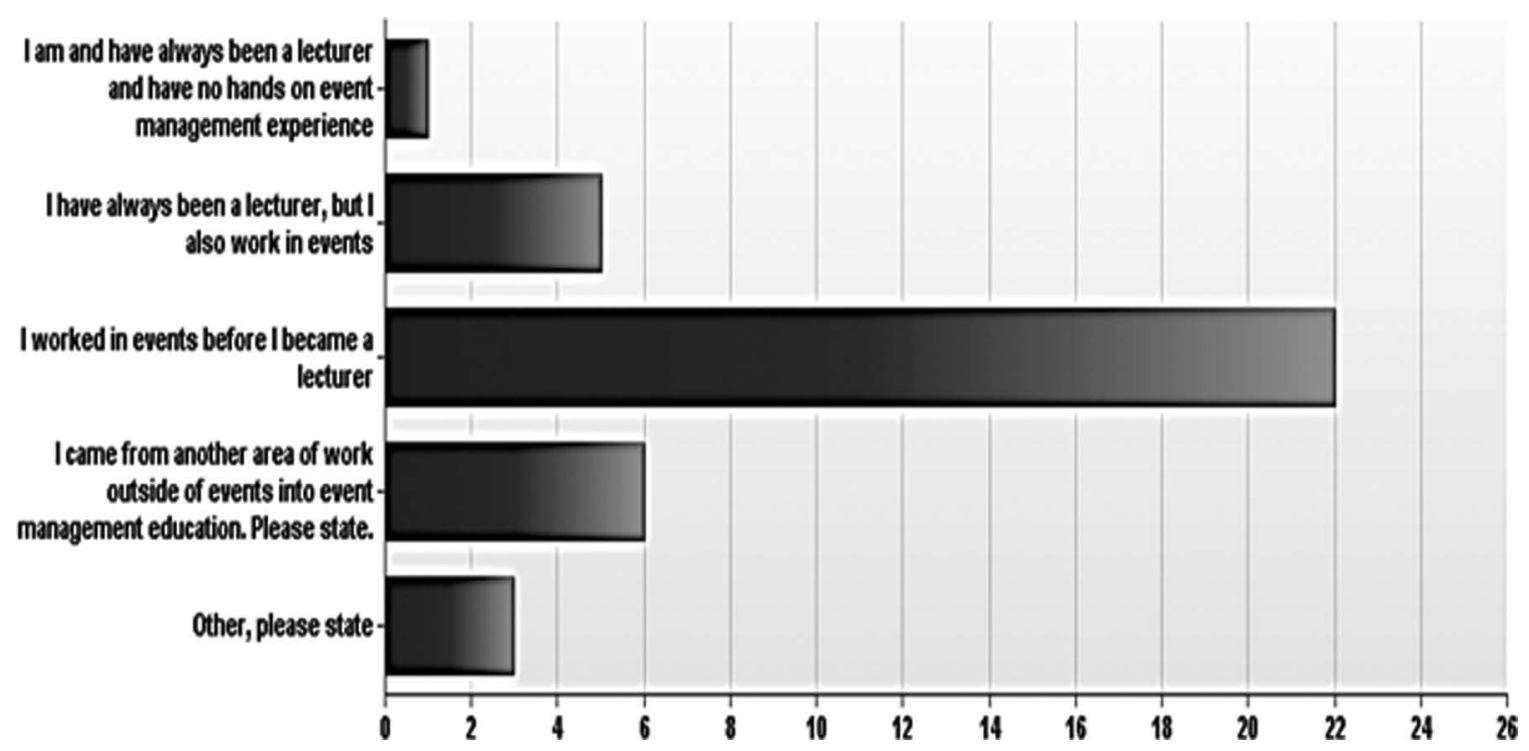

Figure 1. Event management lecturer background and industry experience.

in the delivery of EME awards than responses to this study. Therefore, this study does not claim to address the discussion to any level of certainty. However, the responses received should go some way to reassuring EME stakeholders.

The actual explanation for the negative judgment of EME staff may never properly be established, but could be grounded in a number of explanations. It may be that those in the industry are speaking from experience of EME graduates, or it could be based on an opinion made after meetings between lecturers and people in the industry. Another possibility may be that EME is taught by those who are seen as education specialists (academics) with event industry experience and not considered specialist (professional) enough by the industry to warrant full respect. This research suggests the lack of first-hand experience in event management from EME lecturers is mere conjecture.

To determine the actual subject areas currently taught in EME awards, a comprehensive list of subjects was made available. Table 1 shows the list of options for respondents to choose from based on a number of specific headings to determine if they were teaching their own specialist area, or if they were teaching a subject with limited knowledge. It is appreciated that each institution will have its own title for the module related to each of these subject areas, such as "Festival Operations," which might confuse the answer somewhat. However, these module titles are specific to the institutions' award and the respondent will have a better understanding of the content. Therefore, it is believed the respondent would still be able to comment accordingly. It has been decided to omit a further column that was completed entitled in the study "Not Teaching." Although the data from that column are considered of use to the study, it was deemed to have added little at this stage of inquiry.

While Table 1 reveals the most popular subjects taught, it also reveals the respondents' personal engagement with each subject. Most notably, the areas lecturers consider themselves to be specialists in and not teaching. Each institution will have its own set of processes when developing an award and often a specialist in one area can be fully engaged with other modules and therefore unavailable when the award is reviewed and new topics introduced. New recruitment of staff and other management processes may also contribute to this situation. Similar specialist knowledge areas within a small team or insufficient knowledge of the wider skills and specialisms in a team could contribute to inappropriate allocations being made. Table 1 responses could also bring into question somewhat the quality of education being received in these particular areas. 
Table 1

Areas of Teaching in Event Management

\begin{tabular}{lrllll}
\hline Specialist and Teaching & & \multicolumn{1}{c}{$\begin{array}{c}\text { Specialist and NOT } \\
\text { Teaching }\end{array}$} & $\begin{array}{l}\text { Teaching but With } \\
\text { Limited Knowledge }\end{array}$ \\
\hline Festivals & 15 & Operations & 5 & Sustainability & 9 \\
Operations & 14 & Venue management & 5 & Health \& Safety & 8 \\
Venue Management & 13 & Marketing & 4 & Community events & 7 \\
Marketing & 13 & Cultural events & 4 & Exhibitions & 7 \\
Cultural events & 13 & Logistics & 4 & Sponsorship & 7 \\
Conferences & 12 & Private events & 4 & Conventions & 7 \\
Health \& Safety & 11 & Community events & 3 & Cultural events & 6 \\
Other & 11 & Corporate events & 3 & Fund raising & 6 \\
Exhibitions & 10 & Business start-up & 3 & Festivals & 6 \\
Logistics & 10 & Exhibitions & 2 & Marketing & 5 \\
Community events & 10 & Sustainability & 2 & Public relations & 5 \\
Sustainability & 9 & Theatre \& live arts & 2 & Law & 5 \\
Corporate Events & 9 & Fund raising & 2 & Venue management & 4 \\
Conventions & 8 & Festivals & 1 & Corporate events & 4 \\
Sponsorship & 8 & Conferences & 1 & Conferences & 4 \\
Theatre \& live arts & 7 & Health \& safety & 1 & Promotions & 4 \\
Fund raising & 7 & Sponsorship & 1 & Logistics & 3 \\
Private events & 7 & Public relations & 1 & Private events & 3 \\
Public relations & 6 & Law & 1 & Theatre \& live arts & 3 \\
Law & 5 & Promotions & 1 & Incentive travel & 3 \\
Promotions & 5 & Other & 0 & Business start-up & 2 \\
Incentive travel & 4 & Conventions & 0 & Other & 2 \\
Business start-up & 3 & Incentive travel & 0 & Operations & 1 \\
\hline & & & & & \\
\hline
\end{tabular}

While on the surface these figures could suggest a substandard level of education being provided, the fact that $97 \%$ of the respondents also have practical experience of the events industry should minimize this matter somewhat.

An option of "other" was included for lecturers to provide further suggestions of what they taught but not included in the original table in the questionnaire. Responses included, Production \& Staging, Sports Events, Project Management, Celebratory Events, Event Design, Financial Planning, Project Management, Creativity, Technology, Legacy \& Policy, People Management, Finance \& Strategy, Small Business, Consumer Behavior, and Entrepreneurship. The suggestions highlight a number of issues. None more so than the complexity of teaching the N820 event management award when a specific focus area does not exist. It may also suggest a broad area of event management being taught with a limited team of staff specializing in one or maybe two subjects. Furthermore, there may be a continuing demand to address current issues in events alongside subjects considered to be central to the award. Sustainability and Health \& Safety fall into both these categories and appear predominantly in the "teaching but with limited knowledge" column. This may need to be a consideration for future recruitment policy or alternatively taking into consideration guest sessions and site visits, which can provide a means of focus on subjects outside of the delivery teams specialties. This is discussed later in the study.

By using the list of subjects provided in Table 1, Table 2 focuses on what respondents consider to be the three most important subject areas covered in their award. Their selections have been listed in descending order and each selection is followed by the number of times selected. This is an interesting contrast to Table 1 and reveals a marked consistency across each preference. The single choices may be suggesting personal preferences or that the award actually does have a particular focus. If an undergraduate EME award is a combination of Marketing, Operations, Health \& Safety, and Sustainability, which come out as the preferred selections, a sound grounding in a number of necessary skills and knowledge would appear to be transmitted. However, the question of how these subjects 
Table 2

Most Important Subjects of the Event Management Award

\begin{tabular}{llllll}
\hline Choice 1 & \multicolumn{3}{c}{ Choice 2 } & & Choice 3 \\
\hline Marketing & 8 & Marketing & 5 & Operations & 8 \\
Operations & 5 & Health \& safety & 5 & Health and safety & 7 \\
Health \& safety & 4 & Operations & 4 & Sustainability & 5 \\
Festivals & 4 & Logistics & 4 & Marketing & 3 \\
Law & 3 & Sustainability & 3 & Law & 3 \\
Logistics & 2 & Venue management & 2 & Incentive travel & 1 \\
Finance & 2 & Conferences & 1 & Production and staging & 1 \\
Event operations & 1 & Consumer behaviour & 1 & Project management & 1 \\
Event design & 1 & MiCE & 1 & Event production & 1 \\
Creativity & 1 & Management & 1 & Research & 1 \\
Practical experience & 1 & Sociological perspective & 1 & Conference and meetings & 1 \\
Range of event context & 1 & Business start up & 1 & Festivals & 1 \\
All types of events & 1 & Cultural events & 1 & Corporate & 1 \\
Convention & 1 & Technology & 1 & Critical \& creative thinking & 1 \\
Finance & 1 & Festival & 1 & Cultural events & 1 \\
People management & 1 & Corporate events & 1 & Sponsorship & \\
International events & 1 & Project management & 1 & & \\
Range of event context & 1 & Promotion & 1 & & \\
& & Sponsorship & 1 & & \\
\hline
\end{tabular}

are actually taught forms part of Figure 2 (actual learning approach of event management award) and Figure 3 (desired learning approach of event management award) described below.

Table 2 also included the option "other," which allowed respondents to include a subject choice their own. All of the suggested subjects appear to be a repeat of Table 1's suggestions and may therefore relate to specific modules delivered by the institution. The extra insertions included Event Design, Finance \& Accounting, Creativity, Technology, People Management, Finance \& Strategy, and Entrepreneurship.

Previous research into EME, such as Arcodia and Barker (2003), examined the general skill specification in event management job advertisements and the employability skills and attributes of event managers. Bowdin et al. (2006) explored aspects of event management education from an availability rather than content view, so there is little to compare from these studies. However, Harris and Jago (1999) mapped the event-related subjects taught and discussed a number of previous studies into education in Australia. They identified substantial consistency in the key required training/knowledge domains and emphasized then that if further programs were to be created, they would need to be underpinned by an understanding of the skills required of practitioners in the area. More recently, Eade (2010) revealed the view that industry has expressed a preference in on-the-job training for new recruits to receive training that is tailored to the company's needs. This approach would meet with a broader understanding of the contemporary subjects in EME with industry providing the focus, thereby creating a fit between education and industry need.

To understand the complexities EME faces in maintaining a consistency with developments in industry, it is prudent to consider the Event Management Body of Knowledge (EMBOK). Silvers (2003) defined the knowledge domain structure of event management headed by five associated functional units. Each knowledge domain is accompanied by a number of functional units, which is then supported by a classification or taxonomy of topics that may be adopted as part of an EME curriculum. It may of course be possible for a standard HE undergraduate EME award to successfully cover all of these knowledge domains. However, it is important to consider that the level of knowledge transfer required by either the institution or industry would need to be concentrated on specific elements of EMBOK rather than covering broad sections in lesser detail.

This view is enforced when Mulligan (2010) suggests that for a typical course of study in a HE institution, the domain of "Administration" retains 


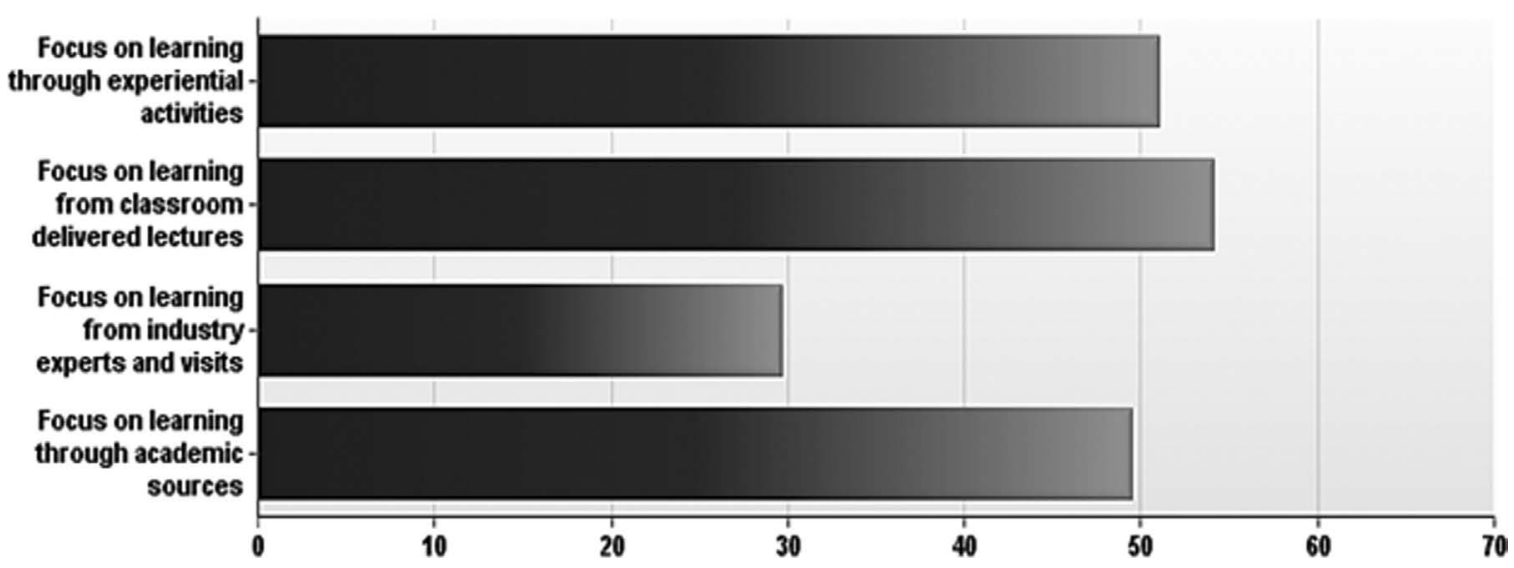

Figure 2. Actual learning approach of event management award.

the highest proportion of course content. This is contrasted with short-course providers in EME that also offer an undergraduate degree through the British Accreditation Council (BAC), where the focus is more on the "Operations" domain for course content. However, EMBOK has been criticized by academics for its vocational and holistic approach (Barron \& Leask, 2012; Bladen \& Kennell, 2014). It is also difficult to ascertain if institutions actually make use of the EMBOK model to design EME awards; although data gathered in this research suggest a high level of synchronization with a number of functional units being applied to each award by EME institutions. The wider extent of this is largely underresearched but considering EMBOK in effect covers all the theoretical possibilities of EME to date, each award reviewed in this research has the appearance of an assortment of the functional areas rather than a dedicated or preplanned alignment with a focus on one of the domains.

Two linked questions were presented to discover: (a) if there were any areas of event management that were not taught that staff considered should be included in the award, and (b) if there were any areas of event management that were taught that staff considered should not be included in the award. Those subjects that were not taught that should be considered included Practical Marketing, Entrepreneurial Development and Financial Management, CSR (corporate social responsibility), Staff Management, People with Special Needs, Business to Business Marketing, Sales Management, Client

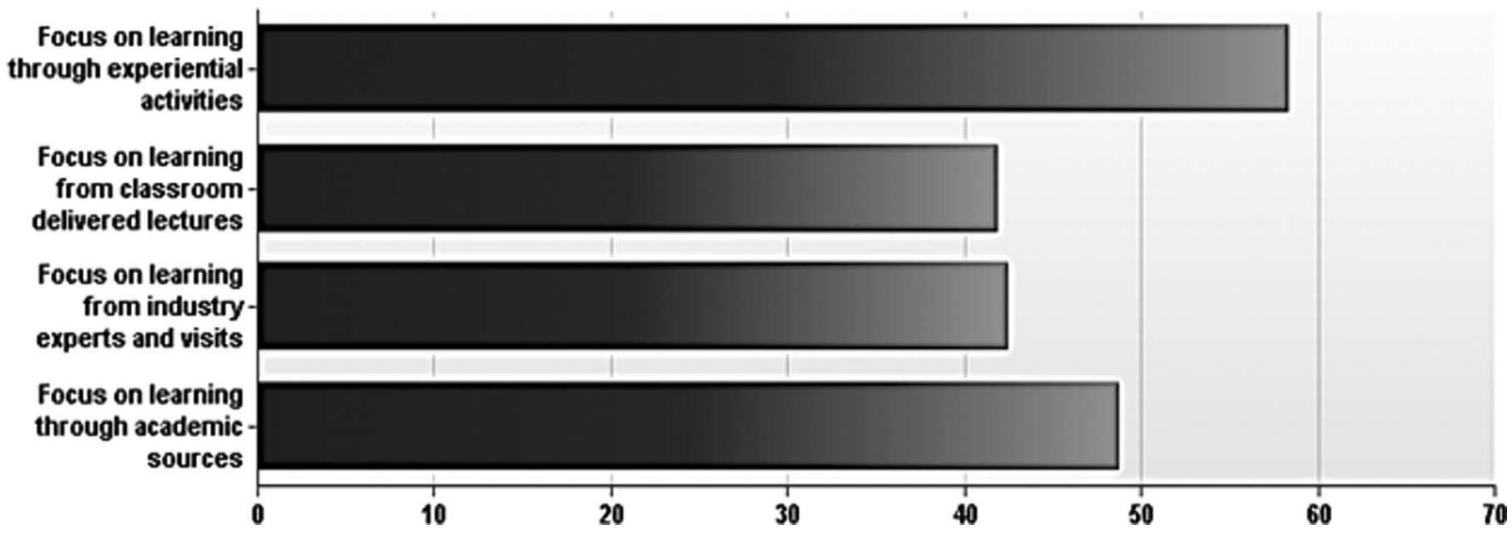

Figure 3. Desired learning approach of event management award. 
Management, Sociology of Events, New Technology, Business Strategy, and Audience Development. Those subjects that were taught that should be removed included Very philosophical discussions, Private Events (especially weddings), Project Management, and Economics.

All of these subjects received single responses and while of interest to those who suggested them, no theme or trend is revealed. It is tempting to discuss these suggestions at length, but because of the need for brevity, they are problematic to analyze in any depth and are best kept to be the subject of further research. However, the data could be unearthing some further questions around the control of the curriculum. It may be difficult to avoid the presence of philosophical discussions and private events (or any other subject for that matter) if other members of the delivery team consider them important. The design of EME awards and the sharing of modules with other business awards is another distinct possibility that could be the basis of many issues. Preferred subjects such as those previously suggested may be excluded as less relevant subjects are remaining on the award from a greater influence within the school.

Following directly on from this question, the questionnaire considered if there could be a distinction between the actual learning focus of the award (Fig. 2) and a desired learning focus of the award (Fig. 3). Respondents were given the opportunity to provide their opinion via a sliding scale between 0 and 100 to rate the value of each part of the delivery process. Each figure shows the average value to the respective question.

When comparing the two figures, the responses suggest that lecturers would prefer an increase in experiential activities by $7 \%$, a reduction in classroom-based lecturing hours by $12 \%$, and support from industry experts and site visits up by $12 \%$. The question on the focus on learning from academic resources remained consistent in both responses.

This preference towards change in the delivery methods supports the suggestion that the present model of the predominantly business-focused awards is outdated (Bladen \& Kennell, 2014). The data presented here are not conclusive, but current delivery practices may be flawed if the teaching method is considered unsuitable. EME lecturers are evidently suggesting the current delivery practices can be improved, but as already discussed, if business schools prefer broad approaches to teaching business management and EME is coupled inside this process, award leaders may be constrained by the school in which the award is based. Some heads of school may consider the present system to offer wider economic benefits across the institution as a whole. It is standard practice for institutions to amend the curriculum through regular and challenging reviews and these offer opportunities for award leaders to submit their preferred direction. However, because of the interplay between the rapidly changing environment of the events industry and the range of forces and factors that shape education, there is a risk that EME award leaders become reactive rather than strategic and forward thinking (Dredge et al., 2013) when reviewing an award.

In planning for the future development of EME, a recent event management NOS steering group meeting (Association for Events Management Education [AEME], 2014) revised the key purpose for event management to "create and deliver opportunities for people to participate in an event to meet audience and stakeholder needs to achieve economic, professional, or social objectives.” Part of the process in achieving this key purpose is for EME to ensure a number of skills, knowledge, and abilities are transferred to current students who will deliver these objectives. There is also considerable evidence of future planning from the continued debate on the professionalization of event management (Arcodia \& Reid, 2003; Bladen \& Kennell, 2014; Brown, 2014; Dredge et al., 2013; Getz \& Wicks, 1994; Jiang \& Schmader, 2014; Royal \& Jago, 1994; Thomas \& Thomas, 2013b). This is a debate that will be significant to the future development of education if achieved. However, Nelson and Silvers (2009) examined event management from a historical perspective, using research in anthropology, sociology of work, professions, and career paths. They distinguished that the field of event management appears not to have reached a number of important milestones indicative of a profession.

With these points in mind, the final two questions were put forward to understand how extensively progressive activities have managed to penetrate EME. Figure 4 asked whether EME awards are designed with the event management NOS in mind 
and Table 3 considers four of the key skills and knowledge areas. The importance of such alignment is emphasized by Fenich (2014), who considers the introduction of event competency standards as "truly the dawning of a new age for meeting and event professionals” (p. 112).

As shown inn Figure 4, more than half the respondents are uncertain whether the NOS are taken into account when designing event management awards, with 6\% (2) unaware of their existence. NOS are considered pivotal for vocational qualifications and can provide considerable guidance for all in the design of awards. Considering these are established with employers, it seems a major oversight for these not to be fully incorporated into award design. The importance of NOS has been emphasized by the Scottish Qualifications Authority (SQA) who explained that:

NOS will ensure that the qualifications are fit for purpose and serve the needs of candidates, employers and the economy. It is very important that everyone involved in the design and development . . . has taken cognizance of NOS at every stage of the qualification's life cycle. (SQA, 2006, p. 1)

With a considerable number of challenges being placed in front of EME today, it is difficult to understand why greater effort is not being made to ensure these developments are communicated more thoroughly to EME staff. It is also worth questioning why a discretionary standard of performance is not adopted in the design of EME awards. The widespread adoption of NOS may be a possible and very straight forward solution considering they relate to the workplace, with specifications that underpin knowledge and understanding (NOS, 2014). However, alignment to NOS should only be the starting point as there is opportunity for EME to go much further.

Communication does exist between EME staff, not least through the AEME. If AEME are in the process of agreeing NOS standards that can revise the key purpose for event management, then there is no reason why a new and dedicated accreditation of EME awards that institutions agree and even aspire to subscribe to should also be put forward. If not an accreditation, a requirement EME awards agree to uphold and demonstrate. AEME (in the UK at least) should naturally be the arbiter of a self-policing quality control for EME; especially considering its aim to "support and raise the profile of the events discipline through the sharing of education and best practice” (AEME, 2014). The potential benefits are considerable and while the

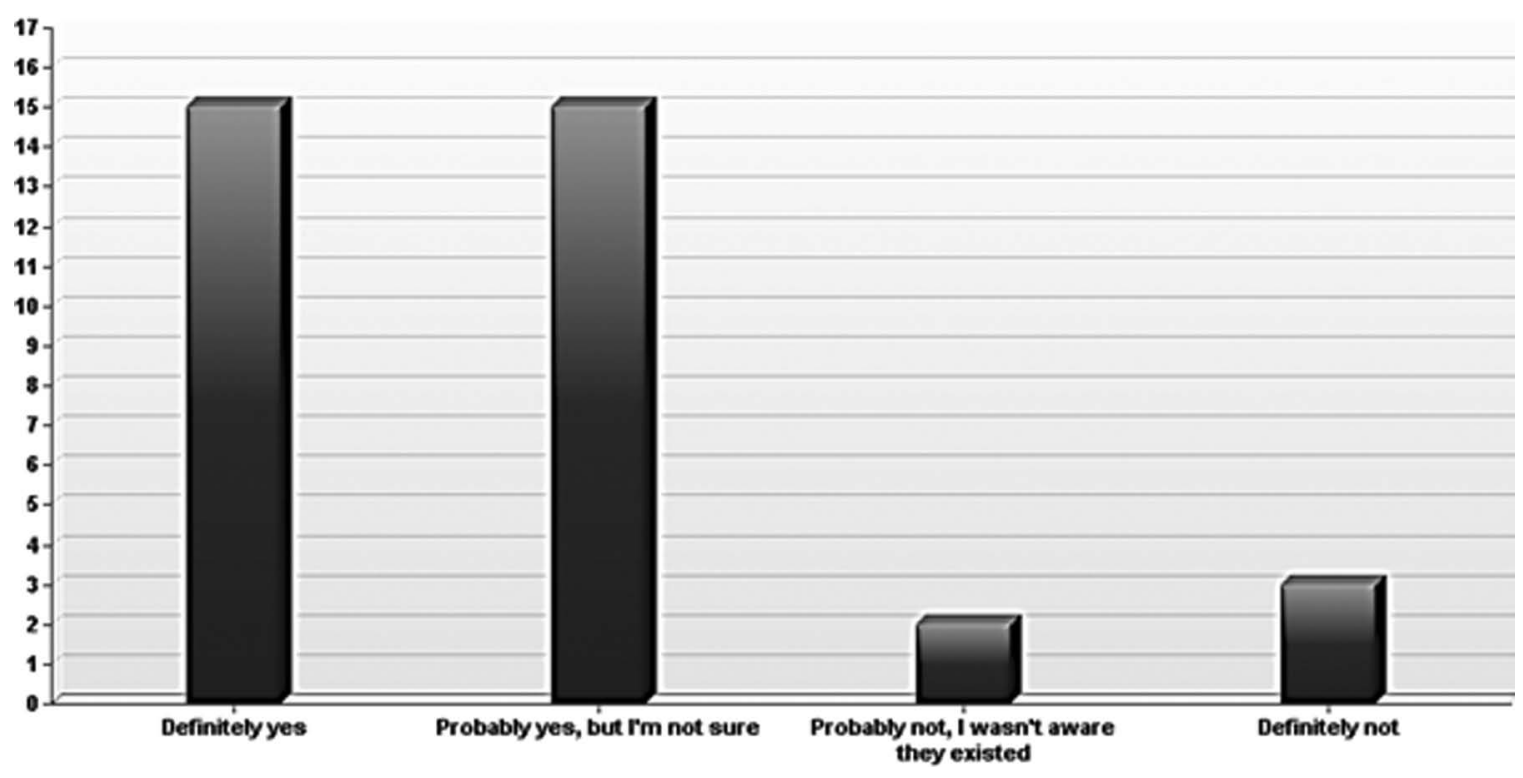

Figure 4. Consideration of the Event Management National Occupational Standards in Award Design. 
Table 3

Ranking of the Four Key National Occupational Standard Roles

\begin{tabular}{|c|c|c|c|c|c|c|}
\hline & $1 \mathrm{st}$ & 2nd & 3rd & 4th & 5th & $\begin{array}{c}\text { Total } \\
\text { Responses }\end{array}$ \\
\hline 1. Managing the creative and commercial aspects of an event & 12 & 6 & 11 & 5 & 0 & 34 \\
\hline 2. Managing event operations & 18 & 8 & 7 & 1 & 0 & 34 \\
\hline 3. Managing event marketing and sales & 3 & 10 & 13 & 6 & 2 & 34 \\
\hline 4. Event evaluation & 1 & 10 & 1 & 22 & 0 & 34 \\
\hline 5. Other, of your choice & 0 & 0 & 2 & 0 & 32 & 34 \\
\hline Total & 34 & 34 & 34 & 34 & 34 & - \\
\hline
\end{tabular}

ability to discuss these appropriately in this article is not available, two key consequences would be: (1) a starting point to advance the quality of EME awards, and (2) stakeholder reassurance. Considering the universal use of accreditation for awards, it is likely that EME institutions would welcome the opportunity to include an accreditation that confirms their EME award was designed based on the education guidance set out by AEME. AEME members would of course have the opportunity to contribute to such a strategy.

Those championing the cause for professionalization may consider the limited certainty in the widespread use of NOS in the design of EME awards problematic. An AEME accreditation may be considered advantageous to the professionalization case. Thomas and Thomas (2013a) recognized that support from industry associations was the basis of a move towards professionalization in Hungary. By starting from within EME itself, it should be considered likely that further support can be obtained from a broader collection of stakeholders.

Taking the NOS question a step further, Table 3 asked respondents to rank the four key NOS roles as suggested in the draft Events Management Sector Functional Map. What is most notable in Table 3 is that Marketing has (not just in previous tables in this study, but consistently throughout numerous studies) remained a choice of preference. However, marketing becomes much less significant when grouped together with Sales and Management. Also, while Figure 4 may suggest a number of issues with award design, the ability to present a focus for the event management award from an "occupational role" perspective is actually achieved. If responses are calculated by weighting the number of 1st, 2nd, and 3rd choices in descending order, two areas become clearly defined. Respondents consider "Managing Event Operations" the most important with "Managing the Creative and Commercial Aspects of an Event" second. These two activity areas relate to experiential learning and this again could be a reflection of the desired approach lecturers would prefer to the design and delivery of future EME awards.

\section{Conclusions}

It is accepted that this study of EME is limited as the sample size is relatively small and therefore the conclusions are not generalizable to a larger population. Also, these are the preliminary findings from an ongoing study into EME and the data continue to be analyzed. However, the preliminary findings have provided some considerable responses to the ongoing questions related to content and quality of EME. Those who teach EME may consider some of the data as welcome relief and feel reassured by some of the findings, including the breadth of industry experience that lecturers have and understanding the importance of the necessary skills required. Furthermore, HEIs and events industry trade associations have recently come together to discuss improving collaborations with the intention of advancing the understanding between the two sectors (BVEP, 2014). But the data also suggests that many issues still remain. The critical appraisal of EME from a small number of stakeholders, while unpleasant, will continue to assist in revealing possible areas of improvement.

The way in which EME is delivered is an area that this research suggests, from the views of those who teach it, would benefit from a reevaluation. Subjects such as Technology, Health \& Safety, Design, and Logistics advance our industry and 
event professionals embrace every possibility to simplify, upgrade, and improve the delivery of events. Without a thorough review of the approach to the delivery of EME, some awards may struggle to keep apace. A continued belief in long-standing education delivery practices that suit general business management awards do not appear to be fully conducive to adequately teaching or testing the necessary skills for event management. This state of affairs cannot be put down simply to the lecturers who teach on EME awards as the case study results suggest progression is sought.

Greater consideration for the nuances of EME from the host institution is the first step forward. This may be a major challenge for some EME award leaders, especially if they do not receive the necessary level of support from their school. But without a thorough review or the adoption of measured regulation, it is difficult to understand how EME can consistently produce graduates that meet the needs of the industry. Moreover, without a consistently dedicated program of teaching that consistently produces graduates who meet the needs of the industry, it is difficult to envisage when the professionalization debate will end.

\section{References}

Association for Events Management Education. (2014). About us. Retrieved May 19, 2014, from http://aeme.org/ about-us/aeme/about-us.html

Arcodia, C. V., \& Barker, T. (2003). The employability prospects of graduates in event management: Using data from job advertisements. In R. W. Braithwaite (Ed.), CAUTHE 2003: Riding the wave of tourism and hospitality research (pp. 1-16). Coffs Harbour, NSW, Australia: CAUTHE.

Arcodia, C. V., \& Reid, S. L. (2003). Professionalising event practitioners: The educational role of event management associations. In K. Weber (Ed.), Advances in Convention, Exhibition and Event Research, Convention and Expo Summit. Hong Kong: The Hong Kong Polytechnic University.

Barron, P., \& Leask, A. (2012). Events management education. In S. J. Page \& J. Connell (Eds.), The Routledge handbook of events (pp. 473-488). Oxon, UK: Routledge.

Benjamin, K. (2014). Confex 2014: Industry experts divided over value of event management degrees. Retrieved March 14, 2014, from http://www.eventmagazine.co.uk/ bulletin/eventnewsbulletin/article/1285148/confex-2014industry-experts-divided-value-event-managementdegrees/?DCMP=EMC-CONEventnewsbulletin
Bladen, C., \& Kennell, J. (2014). Educating the 21st century event management graduate: Pedagogy, practice, professionalism, and professionalization. Event Management, 18, 5-14.

Bowdin, G. A. J, McPherson, G., \& Flinn, J. (2006). Identifying and analysing existing research undertaken in the events industry: A literature review for People 1st. Retrieved March 30, 2013, from www.caledonianblogs. net/ccpe/files/2009/09/Bowdin.pdf

Brown, S. (2014). Emerging professionalism in the event industry: A practitioner's perspective. Event Management, $18,15-24$.

Business Visits and Events Partnership. (2014). Events are GREAT Britain. London, UK: Author.

Complete University Guide. (2014). Univeristy league table. Retrieved March 17, 2014, from http://www.thecomplete universityguide.co.uk/league-tables/rankings

Dredge, D., Benckendorff, P., Day, M., Gross, M. J., Walo, M., Weeks, P., et al. (2013). Drivers of change in tourism, hospitality, and event management education: An Australian perspective. Journal of Hospitality \& Tourism Education, 25, 89-102.

Eade, L. (2010). Highlighting professionalism in event industry. Retrieved from http://www.epmagazine.co.uk/archiveview/highlighting-professionalism-in-the-events-industry/

Edwards, S. (2014). Universities highlight value of event management degrees. Retrieved March 14, 2014, from http://www.eventmagazine.co.uk/universities-highlightvalue-event-management-degrees/careers-workplace/ article/1285630

Fenich, G. G. (2014). The dawning of a new age. Journal of Convention \& Event Tourism, 15, 111-113.

Getz, D., \& Wicks, B. (1994). Professionalism and certification for festival and event practitioners: Trends and issues. Festival Management \& Event Tourism, 1, 163-170.

Giles, C. (2013). A-level students: If you don't get into a Russell Group university, skip going altogether. Retrieved October 18, 2014, from http://www.telegraph.co.uk/com ment/10245793/A-level-students-if-you-dont-get-intoa-Russell-Group-university-skip-going-altogether.html

Harris, R., \& Jago, L. (1999). Tourism events training audit. Tourism New South Wales, Sydney: Events Unit.

International Conference of Events. (2013). Association panel. Making Waves ICE 2013, Bournemouth University, Poole, UK, July 5.

Jiang, J., \& Schmader, S. W. (2014). Event management education and professionalism: The view from the trenches. Event Management, 18, 25-37.

Junek, O., Lockstone, L., \& Osti, L. (2007). Event management education: The student perspective. Fourth international event research conference: Re-evaluating the city/town: Events as a catalyst for change, Victoria University, Melbourne, Australia.

Mulligan, J. (2010). Ivory tower events. Global events congress IV, Leeds Metropolitain University, Leeds, UK, July 14-16.

Nelson, K. B., \& Silvers, J. R. (2009). Event management curriculum development and positioning: A path toward 
professionalization. Journal of Hospitality \& Tourism Education, 21, 31-39.

National Occupational Standards. (2014). What are national occupational standards? Retrieved May 19, 2014, from http://nos.ukces.org.uk/Pages/index.aspx

People1st. (2010). Intelligence and insight on our industries. Retrieved April 22, 2014, from http://www.people1st. co.uk/Research-policy/Research-reports

Perry, M., Foley, P., \& Rumpf, P. (1996). Events management: An emerging challenge in Australian higher education. Festival Management and Event Tourism, 4, 85-93.

Pool, L. D., \& Sewell, P. (2007). The key to employability: Developing a practical model of graduate employability. Education and Training, 49, 277-289.

Presbury, R., \& Edwards, D. (2005). Incorporating sustainability in meetings and event management education. International Journal of Event Management Research, 1(1), 30-45.

Royal, C., \& Jago, L. (1994). Special event accreditation: The practitioners perspective. Festival and Special Events Management, 5, 221-230.
Silvers, J. (2003). Event management body of knowledge domain strucutre. Retrieved March 23, 2014, from http://www.juliasilvers.com/embok.htm\#The_Proposed Knowledge_Domain_Structure

Scottish Qualifications Authority. (2006). Using national occupational standards in the development of SQA group awards. Glasgow, Scotland: Author.

Thomas, R., \& Thomas, H. (2013a). "Hollow from the start?" Professional associations and the professionalisation of tourism. The Service Industries Journal, 34, 38-55.

Thomas, R., \& Thomas, H. (2013b). What are the prospects for professionalizing event management in the UK? Tourism Management Perspectives, 6, 8-14.

Travers, M. (2001). Qualitative research through case studies. London: Sage.

Undergraduate Courses at University and College. (2014). Course search “event.” Retrieved May 15, 2014, from https://www.ucas.com/search/site?keywords=event

Veal, A. J. (2011). Research methods for leisure \& tourism. A pracitcal guide. Harlow, UK: Pearson. 